\title{
Avaliação participativa: análise da primeira oficina do VER-SUS Florianópolis (SC)
}

Participatory evaluation: analysis of the first workshop of the VERSUS Florianópolis (SC)

Marina Bastos Paim1, Douglas Francisco Kovaleski², Rodrigo Otávio Moretti-Pires ${ }^{\mathbf{2}}$

RESUMO A avaliação participativa é uma proposta democrática e emancipatória, que pretende superar a forma normativa de fazer avaliação em saúde. Esta pesquisa deu-se durante um processo avaliativo e formativo, com o projeto Vivências e Estágios na Realidade do Sistema Único de Saúde, em Florianópolis (SC). Relata a experiência da primeira oficina realizada com o grupo, no formato de roda e protagonizada pelos participantes do projeto. Coletivamente, decidiu-se o propósito, o funcionamento e as prioridades deste momento avaliativo. Este escrito sustenta a factibilidade de uma avaliação que envolva os atores para além da coleta de dados e que seja flexível a modificações durante o seu desenvolvimento.

PALAVRAS-CHAVE Avaliação em saúde. Democracia. Participação social.

ABSTRACT Participatory evaluation is a democratic and emancipatory proposal, which aims to overcome the normative way of doing health care evaluation. This research took place during an evaluation and training process, along with the project Experiences and Stages in the Reality of the Unified Health System in Florianopolis (SC). It reports the first experience of the workshop held with the group, in the round conversation format and carried out by the participants of the project. The purpose, functionality and priorities of this evaluation time were decided collectively. This writing supports the feasibility of an evaluation that involves the actors beyond the data collection and that is flexible to changes during its development.

KEYWORDS Health evaluation. Democracy. Social participation.

1 Universidade Federal de Santa Catarina (UFSC) Florianópolis (SC), Brasil. marinabastosp@gmail.com

2 Universidade Federal de Santa Catarina (UFSC) Florianópolis (SC), Brasil. douglas.kovaleski@ufsc.br

3 Universidade Federal de Santa Catarina (UFSC) Florianópolis (SC), Brasil. rodrigo.moretti@ufsc.br 


\section{Introdução}

A história da avaliação, na Europa, começou no século XVIII, com a conformação do Estado Moderno, principalmente na França e na Inglaterra. A preocupação com a avaliação de políticas públicas se iniciou nesses países, na medida em que seus governos começaram a promover políticas de bem-estar SOcial (BROUSSELLE ET AL., 2011).

Esse processo inseriu-se na consolidação do Estado pautado no modo de produção capitalista, promovendo proeminência para pensadores da gestão clássica, tais como: Frederick Taylor (Estados Unidos) e Henri Fayol (França), que lançaram a teoria da administração científica nas primeiras décadas do século XX. Taylor apresentou a perspectiva de padronização dos tempos e movimentos nos processos de trabalho com vistas à melhoria da eficiência do trabalho e a uma maior produtividade dos trabalhadores. Fayol trabalhou no sentido da conformação de entidades organizacionais racionais (BROUSSELLE ET AL., 2011).

As perspectivas teóricas acima tiveram importância decisiva, do ponto de vista teórico e prático da administração pública no ocidente, e consolidaram a administração clássica ou tradicional, em termos de avaliação normativa. Avaliação normativa é aquela que visa, essencialmente, ao cumprimento de metas anteriormente estabelecidas, priorizando o estudo da eficácia a partir de valores e conceitos pré-estabelecidos por governantes ou especialistas no campo da avaliação, sem considerar, prioritariamente, a população beneficiada e os trabalhadores envolvidos na prestação dos serviços de saúde, além de outros agentes, na construção e consecução do processo avaliativo.

Em seus primórdios, a avaliação de políticas públicas resultou na elaboração de testes padronizados e de mecanismos de coleta sistemática de dados, em um paradigma oriundo das ciências naturais. Os campos da educação e da saúde lançaram mão da pesquisa experimental para testar a utilidade das intervenções, identificar causas de problemas e elaborar estratégias de análise e intervenção, em uma perspectiva política que aceitava o Estado e sua relação com a sociedade civil como dada, de caráter reformista e reprodutora do 'modus vivendi' em vigor (GUBA; LINCOLN, 2011).

Na saúde, a influência neoliberal direcionou avaliações realizadas exclusivamente por especialistas, com decisões unilaterais, em busca da padronização de critérios predominantemente quantitativos, na perspectiva de adequar a avaliação ao "[...] uso simplista e acrítico de indicadores" (SOuzA; CUNHA, 2013, P. 660). É possível relembrar como, historicamente, o campo da avaliação foi construído, a partir de Guba e Lincoln (1989), em uma abordagem clássica e recorrente no campo da avaliação em educação, inicialmente focada na realização de exames escolares e testes de aproveitamento, pautada em construir e aplicar instrumentos de medidas. Posteriormente, chegou-se a uma abordagem descritiva, oriunda do questionamento e da necessidade de aperfeiçoar os currículos escolares, verificando-se o cumprimento do que era esperado, surgindo, assim, a avaliação de programas, superando a simples utilização de medidas, em que o avaliador cumpria também a função de descritor. E, em seguida, o avaliador assumiu o papel de julgador, a partir de critérios pré-definidos, para a tomada de decisão, ou seja, o juízo de valor tornou-se parte essencial da avaliação (GUBA; LINCOLN, 2011).

Nesse panorama histórico, é interessante notar que houve pouco envolvimento e inclusão dos diversos atores implicados no que se buscava avaliar, um efeito da crença em uma verdade única e absoluta, constituída sobre uma fundamentação de pressupostos positivistas, para os quais a ciência é isenta de valores, gerando uma dependência em relação à mensuração quantitativa. A utilização de dados pressupõe dados quantificáveis, medidos com precisão e analisados 
com instrumentos estatísticos (FURTADO, 2008; WESTPHAL; MENDES, 2009; GUBA; LINCOLN, 2011).

No período mais recente, a ênfase volta-se para perspectivas participativas de avaliação, com o intuito de superar a avaliação pautada em um paradigma reducionista e positivista, através de um processo que leve em conta a produção de subjetividades durante o processo de avaliar. A avaliação participativa se torna cada vez mais reconhecida e utilizada, pois envolve os atores do contexto da intervenção, o que também facilita o uso dos resultados oriundos da avaliação (UCHIMURA; BOSI, 2002; FURTADO, 2008; WESTPHAL; MENDES, 2009; FURTADO ET AL., 2013).

\section{Avaliação participativa}

Durante a avaliação participativa, outros atores sociais constroem a avaliação, além dos avaliadores, como a comunidade, os trabalhadores e os gestores. No entendimento de Furtado e Campos (2008, P. 2), "[...] participação é uma condição necessária a uma política social realmente comprometida com mudanças sociais”. Sendo assim, a avaliação participativa sugere uma reformulação na prática da pesquisa, pois se propõe a fazer junto, oferecendo a oportunidade de setores marginalizados influenciarem a formulação, a execução e a avaliação de políticas sociais (FURTADO; CAMPOS, 2008; FURTADO, 2008; WESTPHAL; MENDES, 2009; FURTADO, 2011).

A avaliação participativa torna a avaliação uma construção coletiva, composta por diversos atores. Nela, o pesquisador não detém o monopólio do método avaliativo, incorporando aqueles que conhecem a realidade estudada. Não envolve os atores apenas na coleta de dados, mas valoriza o debate e a construção coletiva do conhecimento, visando aumentar o poder dos participantes por meio do processo avaliativo. Auxilia os grupos a compreenderem melhor o problema e a pensarem alternativas de como modificá-lo. Propõe a emancipação dos envolvidos e o controle conjunto da avaliação, que irão se identificar com os resultados e as recomendações, tornando a avaliação útil à ação futura. Pois, a participação da sociedade civil organizada, em todas as etapas da avaliação, auxilia no avanço para a etapa do agir (BARON; MONNIER, 2003; BROUSSELLE ET AL., 2011; TINÔCO; SOUZA; OLIVEIRA, 2011; FURTADO ET AL., 2013).

A avaliação participativa pretende ir além do simples acúmulo de dados, pretende uma solução comum. Por isso, se propõe a uma negociação com diversos interessados, na qual o avaliador cumpre o papel de mediador da avaliação. O envolvimento de diversos atores em todo o processo avaliativo visa potencializar o programa, visto que o objeto pode ser percebido de maneiras muito diferentes pelas pessoas, aumentando também a propriedade, por parte do coletivo, em relação ao programa e à credibilidade dos resultados (FURTADO, 2008; FURTADO; CAMPOS, 2008; WESTPHAL; MENDES, 2009; FURTADO, 2011).

Tem como um dos seus objetivos ser formativa, pois foca no processo - não apenas no resultado - e na busca do consenso ou esclarecimento das diferentes visões. $\mathrm{E}$ promove o diálogo necessário para construções e reconstruções coletivas. Além disso, os grupos de interesses auxiliam no processo da avaliação, que pauta-se no pressuposto de que tal processo envolve a construção de laços sociais e de aspectos (inter)subjetivos, não apenas construindo o objeto da avaliação durante o processo, mas também provocando mudanças nos envolvidos. Além de ser um intenso processo formativo, a avaliação participativa ainda favorece a apropriação, por parte dos atores, das informações geradas, de maneira a compreender e a intervir sobre o problema identificado, até mesmo organizando futuras avaliações (FURTADO, 2001; FURTADO, 2008; FURTADO; CAMPOS, 2008; WESTPHAL; MENDES, 2009; FURTADO, 2011; MEIRELLES; HYPOLITO; KANTORSKI, 2012).

Sendo assim, a avaliação participativa, como proposta democrática, emancipatória e de autonomia dos sujeitos, trabalha na 
tentativa de modificar o estabelecimento das relações de poder. Com este enfoque, a presente pesquisa empregou a avaliação participativa em concordância com a proposta do objeto de avaliação, o projeto de extensão Vivências e Estágios na Realidade do Sistema Único de Saúde (VER-SUS) em Florianópolis (SC), da Universidade Federal de Santa Catarina (UFSC).

\section{O projeto VER-SUS}

O VER-SUS é uma estratégia de educação permanente, que nasce do movimento estudantil e é apoiado pelo Ministério da Saúde. Iniciou em 2004 e foi retomado em 2011, com o objetivo de aproximar estudantes universitários, de várias áreas de conhecimento, da realidade e do cotidiano do Sistema Único de Saúde (SUS) (FERLA ET AL., 2013B; TORRES, 2013).

O projeto começou no Rio Grande do Sul e se expandiu nacionalmente, na perspectiva de formar para o SUS e estimular as mudanças curriculares, utilizando práticas pedagógicas transformadoras. Caracterizou-se por oportunizar vivências, propiciar o contato com o mundo do trabalho e permitir uma interação multiprofissional e interdisciplinar, um cenário de aprendizagem que parte da experimentação e da reflexão crítica. Adotou a intenção de fortalecimento do protagonismo do estudante, pressupondo que, ao tomar parte, o grupo tem condições de pensar a sua própria formação, com a intenção de questionar as práticas pedagógicas que não levam em conta o estudante como sujeito ativo do processo de construção do seu próprio conhecimento (CANÔNICO; BRÊTAS, 2008; FERLA ET AL., 2013A; FERLA ET AL., 2013B).

Esta iniciativa permite experimentar novos espaços de aprendizagem, o trabalho em equipe e a correlação dos conhecimentos das diferentes áreas. Age como uma tentativa de desconstruir a fragmentação do ensino e do trabalho em saúde, de estimular o trabalho coletivo e construir uma nova visão do que é saúde. O VER-SUS pretende

[...] mobilizar efetivamente corações e mentes para o fortalecimento e a defesa do SUS, tanto nas suas dimensões técnicas e cotidianas, quanto na militância política. (FERLA; MATOS, 2013, P. 114).

O VER-SUS agrega estudantes, professores, movimentos sociais e serviços de saúde, orientado pela construção coletiva e pela relação horizontal entre os diferentes atores, estruturando-se em momentos de reflexão, troca de experiências, problematização, construção coletiva dos saberes e estímulo à formação de vínculos, em uma aprendizagem que sensibiliza o estudante para uma atuação mais ativa na universidade e como profissional de saúde (FERLA ET AL., 2013A; FERLA ET AL., 2013B).

Tais estágios de vivências se diferenciam dos estágios curriculares ofertados nos cursos de graduação, pois o movimento estudantil atua com protagonismo na sua organização e execução; a vivência pretende

[...] provocar incômodo, desestabilizar os pré-conceitos, as pré-concepções e permitir ao estudante novas formas de experimentar o ensino [...]. (TORRES, 2013, P. 11).

Esta iniciativa, na qual o estudante tem um papel ativo, gera conflitos, mas pretende desestabilizar a relação vertical entre professor e estudante, pois muda a função tradicional de ambos, durante o processo ensino-aprendizagem, cuja transmissão do conteúdo

[...] constitui o próprio fim da existência escolar; o estudante, por sua vez, é submetido a absorver o conhecimento que o professor detém, idealizando a concepção de que apenas esse tem o potencial para transmitir conhecimento. (CANÔNICO; BRÊTAS, 2008, P. 260). 
A proposta é de uma aprendizagem significativa, um aprendizado que produz e tem sentido para o estudante; pressupõe o encontro com o novo, a sensação de incomodo em um cenário novo, que permite acumular experiências e vivências (CECCIM, 2008).

O projeto vem sendo implementado por coletivos organizados - comissões organizadoras - de forma descentralizada pelo País, de acordo com a conjuntura local, que se apoia em diretrizes nacionais. A comissão organizadora previamente identifica os locais de vivência, e as visitas acontecem durante uma imersão nas férias de verão e de inverno; o tempo varia conforme cada experiência, mas, normalmente, entre 7 e 15 dias. Estas visitas são oportunidades de integração entre estudantes, profissionais de saúde, gestores, docentes e usuários, verdadeiros momentos de trocas (FERLA ET AL., 2013A; FERLA ET AL., 2013B; TORRES, 2013; FERLA ET AL., 2013C).

Podem participar estudantes de graduação selecionados em todas as áreas do conhecimento. Estes compõem o grupo dos viventes, que é acompanhado pelo facilitador, um estudante que já participou de outras edições do projeto. Ele faz a mediação com os locais de vivência, incentiva a reflexão crítica sobre o que foi visto durante as discussões do grupo, que são realizadas no final de cada dia, e auxilia nas formações de sensibilização e aprofundamento teórico, realizadas previamente às vivências (TORRES, 2013; FERLA ET AL., 2013B).

\section{Métodos}

A construção de uma avaliação participativa, de caráter formativo, realizou-se mediante um processo interativo e protagonizado pelos envolvidos no contexto, a partir do diálogo contínuo. Sendo assim, um observador pretensamente neutro, distante do objeto, e que tem como meta revelar a 'verdade', não se encaixa nesta visão. A mediação foi fundamental durante a negociação entre os participantes, pois teve a intenção de alcançar o consenso, mesmo que isso consumisse mais tempo e recursos, visto que a avaliação deve ser um processo contínuo, que nunca se completa. Por isso, optou-se por uma pesquisa avaliativa, que incluiu os atores da intervenção no processo avaliativo, viabilizando e ampliando a utilização dos resultados originados da avaliação, levando em conta as características políticas e as especificidades do objeto, além de provocar o processo formativo dos envolvidos no programa avaliado (FURTADO, 2001; FURTADO, 2011).

Sendo assim, o caráter formativo dessa avaliação estimulou a problematização do objeto avaliado, pautada em trabalho coletivo, por meio do diálogo e da reflexão, que, a partir da interação dos atores, oportunizou a resolução dos conflitos. Construiu-se uma avaliação na qual a tomada de decisão foi compartilhada, na perspectiva de redirecionar a prática e intervir sobre o projeto (SILVA, 2010).

\section{A oficina}

Para viabilizar um trabalho coletivo, entende-se que um processo estruturado e fechado com antecedência não combina com o inesperado e as diversas trocas provenientes do grupo. Neste sentido, o formato da avaliação precisa dar abertura a essas mudanças e ter firmeza para manter o processo acontecendo. Por isto, a escolha por métodos qualitativos, pois estes consideram essa interação inevitável e necessária, entre o pesquisador, o objeto e o contexto, facilitando a flexibilidade imprescindível a avaliações participativas, dando permeabilidade para modificações durante o desenvolvimento do trabalho (FURTADO, 2011).

Para constituir um espaço participativo, o instrumento utilizado precisa ir além dos comitês tradicionais, ou seja, a grande questão é elaborar espaços que possibilitem a construção coletiva. Por isto, optou-se por construir momentos de discussão e criação, 
através de oficinas em formato de roda, oficinas caracterizadas por serem pluridimensionais, criativas e coletivas, o que desafiou o modo de trabalhar tradicional e inflexível (FURTADO, 2001; FURTADO, 2011; FURTADO ET AL., 2013).

A roda serve para alimentar circuitos de tro$\mathrm{ca}$, mediar aprendizagens recíprocas e/ou associar competências. É por estarem em roda que os parceiros criam possibilidades à realidade, recriam a realidade e/ou inventam realidades segundo a ética da vida que se anuncia nas bases em que são geradas. [...] Todos os que entram na roda têm poderes iguais sobre o território de que falam. (CECCIM; FEUERWERKER, 2004, P. 57).

Neste artigo, será descrita a primeira oficina realizada com o grupo, a fim de analisar esta experiência, ilustrando uma possibilidade de início de um processo avaliativo participativo. O presente trabalho é parte de um processo avaliativo mais abrangente, um projeto de pesquisa desenvolvido durante 2015 e 2016, que envolve a avaliação do projeto VER-SUS em Florianópolis (SC). A oficina inicial foi o primeiro contato com o grupo e teve por objetivo identificar o propósito e o funcionamento da avaliação. Toda a discussão foi gravada e transcrita posteriormente. Algumas falas foram reproduzidas neste artigo, mantendo o anonimato dos participantes e sem a preocupação de diferenciá-los, pois todas foram consideradas falas do grupo.

Os estudantes que constroem o VER-SUS Florianópolis (SC) constituíram o grupo inicial deste processo avaliativo, visto que estão envolvidos na realização do projeto, como comissão organizadora e facilitadores, e beneficiam outros estudantes, os viventes. Sendo assim, os estudantes são um grupo de interesse importante, que possui grande poder de decisão sobre os rumos do projeto e, a partir deles, são identificados os demais atores.

Foi preciso promover as condições necessárias para estimular a participação dos envolvidos nas oficinas, como escolher adequadamente o dia da semana que possibilitasse a presença de todos, alimentação, local de fácil acesso etc. Dessa forma, foram contatados, por meio da rede social adotada pelo grupo, 41 estudantes e o coordenador do projeto, para pactuar data, horário e local que contemplassem a maior parte dos interessados.

E assim, em um sábado pela manhã, em uma sala de aula do Centro de Ciências da Saúde, deu-se início à oficina, com 22 presentes se aglomerando ao redor do café e do lanche para conversar. Os participantes eram estudantes da UFSC, graduandos em Nutrição, Farmácia, Psicologia, Ciências Sociais, pós-graduandos em Saúde Coletiva e residentes em Saúde Multiprofissional. A fim de organizar as dinâmicas, facilitar e esquematizar as construções do grupo, elaborou-se um roteiro com as atividades a serem desenvolvidas durante a oficina.

Esta pesquisa foi submetida e aprovada pelo Comitê de ética da UFSC, sob o parecer número 1.249.439, e durante a sua execução os participantes assinaram o Termo de Consentimento Livre e Esclarecido.

\section{Resultados e discussão}

Com o propósito de superar os desafios de estabelecer uma construção participativa, criou-se um espaço de diálogo onde todos poderiam se sentir à vontade para contribuir, uma roda de conversa acolhedora a todas as falas, pois o que tornaria a experiência enriquecedora seria o fato de que, durante o processo, todos estariam aptos a incorporar opiniões antes não formuladas (FURTADO, 2011).

A dinâmica introdutória teve por objetivo restabelecer, nos participantes, a percepção sobre o que é uma avaliação, pois esta costuma originar resistências, pelo fato de estar muitas vezes associada a práticas autoritárias e de controle, caracterizada pela 
“[...] submissão a um juízo de autoridade estabelecido por alguém que se baseia em seus próprios critérios" (FURTADO, 2008, P. 716). Para estimular o diálogo, a atividade começou em duplas. Depois, as ideias foram compartilhadas no grupo, mediante relatos de algumas experiências avaliativas anteriores. No início, a timidez era marcante, mas logo começaram a surgir lembranças referentes ao termo avaliação:

[...] a gente não deixou de pensar em provas, avaliação, disciplinas, na faculdade, e de avaliações daquele tipo: bom, muito bom, ruim, em que tu marca um ' $x$ ', e tens um negócio fechado [...] tem essa necessidade de criar um porcentual, de criar um número, de criar coisas que tu vai quantificar [...].

As falas demonstraram que a percepção construída pelos estudantes em torno da palavra avaliação remete a processos fechados, unilaterais e preocupados em quantificar resultados. Esta percepção está vinculada às experiências desses estudantes no cotidiano dos cursos de graduação da área da saúde.

No momento seguinte, a oficina avançou, no sentido de pensar no propósito da construção dessa avaliação do VER-SUS, em suas implicações e nas especificidades do projeto.

[...] a nossa avaliação não precisa ser pontual, visto que a avaliação é um processo constante, mas, às vezes, é preciso materializar esse processo [...] pode ser uma avaliação mais descritiva, construída através do debate, garantindo um espaço para superar as dificuldades [...].

Sendo assim, o grupo concordou em construir um processo avaliativo, e não apenas um momento isolado, entendendo a necessidade de fazer uma avaliação qualitativa, que acompanhasse o ritmo do grupo, de modo a aprofundar as discussões, trazer acúmulos e avanços para o projeto.
[...] temos clareza que a avaliação muda. Dependendo do ponto de vista, estaremos construindo os parâmetros, a partir das nossas experiências, levando em conta a subjetividade do grupo [...] construir esse processo de avaliação é diferente de quando ele já vem pronto, é possível ter noção da implicação social dessa avaliação, pois a avaliação parte de quem realmente faz, de quem está implicado, que, neste caso, é o movimento estudantil [...] a própria discussão já constrói algo dentro do grupo, produzindo consequências no nosso projeto e nos próprios participantes, pois resulta de uma construção conjunta [...].

As falas referem-se às expressões de entendimento do que é construir uma avaliação participativa, a partir de um processo dialógico, feito com e para o coletivo, sem determinações apriorísticas, de acordo com a subjetividade e os valores do grupo implicado na avaliação. Essa reflexão crítica sobre a condução da avaliação provocou uma série de questionamentos sobre o foco do processo avaliativo e sobre como o projeto se dá na prática:

[...] avaliar a transformação que o VER-SUS traz? [...] se ele é construído por estudantes? [...] avaliar a forma que o VER-SUS é feito? [...] avaliar o quanto Florianópolis teve e tem influência nos outros VER-SUS de Santa Catarina?

Concluiu-se, a partir dessas reflexões, que o maior empecilho para avaliar o projeto em Florianópolis (SC), é que mesmo existindo um consenso sobre o que é o VER-SUS para os estudantes que dele participaram, esta definição não está desenvolvida e elaborada, afinal, o projeto possui um caráter pragmático e ocupa-se, fundamentalmente, com a formação e a organização das vivências. E esta conjuntura não é exclusiva de Florianópolis (SC). No âmbito estadual e nacional, o projeto também possui escassez de documentos oficiais que o detalhem. De acordo com o contexto, o projeto varia e tal peculiaridade, em certa medida, se justifica 
porque "[...] está em constante amadurecimento, pelas pessoas que o constroem [...]".

Porém, para avaliar um projeto, é essencial certa organização e consenso entre os envolvidos, sobre seus objetivos e os resultados pretendidos (FURTADO, 2001). Um momento de conversa para a caracterização e a compreensão do grupo sobre o projeto é uma necessidade evidente, por isso, concordou-se em realizar um resgate histórico, elaborar uma concepção coletiva, definir seus objetivos e orientações políticas e de funcionamento. Tudo isso foi realizado junto aos demais grupos de interesse, para somente então decidir-se o foco do processo avaliativo. E, por consenso, o critério de seleção foi participar ou já ter participado da construção do VER-SUS em Florianópolis (SC). O grupo identificou o representante do Ministério da Saúde que trouxe a proposta do VER-SUS para a UFSC, três professores, três funcionários da pró-reitora de extensão que auxiliam na coordenação, dois profissionais da rede municipal de saúde e estudantes envolvidos. Vale ressaltar que esse processo sempre ajuda a dirimir conflitos e fragilidades, constituindo-se em um caminho extenso, mas de grande desenvolvimento e mobilização do grupo, o que pode fortalecer o projeto.

Por fim, vale dizer que, apesar das potencialidades que a avaliação participativa possibilita à construção e ao aprimoramento de políticas, essa perspectiva avaliativa não é positiva em si, pois frequentemente constitui-se em um simulacro, gerando a ilusão de um processo participativo. Um dos desafios é, de fato, agregar os participantes, de modo a reforçar a cultura da participação e da coletividade. Para fugir dessa limitação, devem ser recusados os espaços burocráticos, tendenciosos e manipulados pelo poder estatal de forma antidemocrática, como acontece frequentemente em instâncias oficiais de participação, tais como os conselhos de saúde (BURSZTYN; RIBEIRO, 2005).

A partir do exposto, pode-se afirmar que a primeira etapa do processo avaliativo em análise teve uma configuração que propiciou a negação do simulacro. O grupo de estudantes - protagonistas do projeto e os mais implicados e preocupados com a dimensão política do VER-SUS e sua avaliação - teve espaço físico e político para se colocar e fugir dos aspectos negativos da institucionalidade. Entende-se que este tenha sido um começo exitoso, e o desafio que se segue é o de dar continuidade a esse processo com uma postura democrática, horizontal e participativa.

\section{Considerações finais}

A partir dessa experiência participativa e formativa, conclui-se que é factível realizar uma avaliação que envolva os atores para além da coleta de dados, que retire o monopólio do pesquisador sobre o método avaliativo. Foi possível observar uma avaliação flexível a modificações durante o desenvolvimento do trabalho, para além do simples acúmulo de dados, o que possibilita o diálogo entre os atores, na perspectiva de construir e reconstruir, em busca de uma solução comum e de esclarecimentos das diferentes visões.

Nesse contexto, o envolvimento dos atores não foi superficial, pois foi construído por aqueles inseridos no projeto. E, com certeza, o que viabilizou a participação foi o acordo conjunto sobre a oficina, abrangendo local, dia e horário. O limite, entretanto, está em garantir a continuidade da pesquisa: que se mantenha a participação (tanto na presença como no interesse) desses atores, assim como se consiga envolver os novos, ou seja, os atores identificados nessa oficina. Pois, um dos desafios de tal processo, além de convencer os atores a aderirem à avaliação, é criar um sentimento de responsabilidade, comprometimento e motivação compartilhada, de transformar e trazer avanços para o projeto, para os participantes, para uma nova forma de avaliar. 


\section{Colaboradores}

Marina Bastos Paim contribuiu substancialmente para a concepção, o planejamento, a análise e a interpretação dos dados; na elaboração do rascunho e revisão crítica do conteúdo; participou da aprovação da versão final do manuscrito.

Douglas Francisco Kovaleski contribuiu substancialmente para a concepção, o planejamento, a análise e a interpretação dos dados; na elaboração do rascunho e revisão crítica do conteúdo; participou da aprovação da versão final do manuscrito.

Rodrigo Otávio Moretti-Pires contribuiu substancialmente na elaboração do rascunho e revisão crítica do conteúdo; participou da aprovação da versão final do manuscrito.

\section{Referências}

BARON, G.; MONNIER, E. Une approche pluraliste et participative. Coproduire l'évaluation avec la société civile. Informations socials, n. 110, sept. 2003. Disponível em: $<$ https://www.perfeval.pol.ulaval.ca/ sites/perfeval.pol.ulaval.ca/files/publication_90.pdf> Acesso em: 15 nov. 2016.

BROUSSELLE, A. et al. (Org.). Avaliação: conceitos e métodos. Rio de Janeiro: Editora Fiocruz, 2011.

BURSZTYN, I.; RIBEIRO, J. M. Avaliação participativa em programas de saúde: um modelo para o Programa de Saúde do Adolescente. Cad. Saúde Pública, Rio de Janeiro, v. 21, n. 2, p. 404-416, 2005.

CANÔNICO, R. P.; BRÊTAS, A. C. P. Significado do Programa Vivência e Estágios na Realidade do Sistema Único de Saúde para formação profissional na área de saúde. Acta Paul Enferm., São Paulo, v. 21, n. 2, p. 256$261,2008$.

CECCIM, R. B. A emergência da educação e ensino da saúde: interseções e intersetorialidade. Ciência $\mathcal{E}$ Saúde, Porto Alegre, v. 1, n. 1, p. 9-23, jan./jun. 2008.
CECCIM, R. B.; FEUERWERKER, L. C. M. O

Quadrilátero da Formação para a Área da Saúde: Ensino, Gestão, Atenção e Controle Social. Physis, Rio de Janeiro, v. 14, n. 1, p. 4165, 2004.

FERLA, A. A.; MATOS, I. B. Afinal, o que podem as vivências e estágios na realidade do sistema único de saúde (VER-SUS) para a formação na saúde? In: FERLA, A. A.; ROCHA, C. M. F.; SANTOS, L. M. (Org.). Integração ensino-serviço: caminhos possíveis? Porto Alegre: Rede UNIDA, 2013. (Cadernos da Saúde Coletiva; v. 2).

FERLA, A. A., et al. Vivências e Estágios na Realidade do SUS: educação permanente em saúde e aprendizagem de uma saúde que requer integralidade e trabalho em redes colaborativas. Rev. Eletrôn. Comun. Inf. Inov. Saúde, Rio de Janeiro, v. 7, n. 4, dez. 2013a. Disponível em: <http://www.reciis.icict.fiocruz.br/ index.php/reciis/article/view/510/1157>. Acesso em: 15 nov. 2016.

FERLA, A. A. et al. (Org.). VER-SUS Brasil: cadernos de textos. Porto Alegre: Rede Unida, 2013b. 
FURTADO, J. P. Avaliação de Programas e Serviços. In: CAMPOS, G. W. S. et al. (Org.). Tratado de Saúde Coletiva. 2. ed. São Paulo: Hucitec, 2008.

Avaliação e Participação. In: BRANDÃO, D.; MARTINA, R. O. (Org.). Avaliação de Programas e Projetos: temas brasileiros. São Paulo: Instituto Fonte e Fundação Itaú Social, 2011.

Um método construtivista para a avaliação em saúde. Ciência \&t Saúde Coletiva, Rio de Janeiro, v. 6, n. 1, p. 165-181, 2001.

FURTADO, J. P.; CAMPOS, R. O. Participação, produção de conhecimento e pesquisa avaliativa: a inserção de diferentes atores em uma investigação em saúde mental. Cad. Saúde Pública, Rio de Janeiro, v. 24, n. 11, p. 2671-2680, nov. 2008.

FURTADO, J. P. et al. A elaboração participativa de indicadores para a avaliação em saúde mental. Cad. Saúde Pública, Rio de Janeiro, v. 29, n. 1, p. 102-110, jan. $2013 c$.

GUBA, E. G.; LINCOLN, Y. S. Avaliação de quarta geração. Título original: Fourth Generation Evaluation. Campinas: Editora da Unicamp, 2011.

MEIRELLES, M. C. P.; HYPOLITO, A. M.; KANTORSKI, L. P. Avaliação de quarta geração: reciclagem de dados. J. Nurs. Health, Pelotas, v. 2, n. 1, p. $63-74,2012$.

SILVA, V. M. N. O caráter formativo da avaliação nas práticas avaliativas da gestão da atenção básica de Piraí/RJ: o cotidiano dos atores na perspectiva da integralidade. 2010. 136 f. Dissertação (Mestrado em Saúde Coletiva) - Universidade Federal Fluminense, Niterói, 2010.
SOUZA, T. P.; CUNHA, G. T. A gestão por meio da avaliação individualizante e competitiva como elemento comum nas políticas públicas e gerenciais contemporâneas: uma contribuição crítica a partir de Michel Foucault. Saúde em Debate, Rio de Janeiro, v. 37, n. 99 , p. 655-663, 2013.

TINÔCO, D. S., SOUZA, L. M., OLIVEIRA, A. B. Avaliação de políticas públicas: modelos tradicional e pluralista. R. Pol. Públ., São Luís, v. 15, n. 2, p. 305-313, jul./dez. 2011.

TORRES, O. M. Os estágios de vivência no Sistema Único de Saúde do Brasil: caracterizando a participação estudantil. Rev. Eletrôn. Comun. Inf. Inov. Saúde, Rio de Janeiro, v. 7, n. 4, dez. 2013. Disponível em: <http://www.reciis.icict.fiocruz.br/index.php/ reciis/article/view/571/1212>. Acesso em: 15 nov. 2016.

UCHIMURA, K. Y.; BOSI, M. L. M. Qualidade e subjetividade na avaliação de programas e serviços em saúde. Cad. Saúde Pública, Rio de Janeiro, v. 18, n. 6, p. 1561-1569, nov./dez. 2002.

WESTPHAL, M. F.; MENDES, R. Avaliação participativa e a efetividade da promoção da saúde: desafios e oportunidades. Boletim Técnico do SENAC, Rio de Janeiro, v. 35, n. 2, maio/ago. 2009. Disponível em: <http://www.producao.usp.br/bitstream/ handle/BDPI/14443/art_WESTPHAL_Avaliacao_ participativa_e_a_efetividade_da_promocao_2009. pdf? sequence=1>. Acesso em: 15 nov. 2016.

Recebido para publicação em abril de 2016

Versão final em setembro de 2016

Conflito de interesses: inexistente

Suporte financeiro: não houve 